\title{
THE EFFECTS OF HEAVY METALS AND TEMPERATURE ON MICROBIAL GROWTH AND LAG
}

\author{
P. GIKAS $S^{1,2, \#, *}$ \\ S.S. SENGÖR ${ }^{1}$ \\ T. GINN ${ }^{1}$ \\ J. MOBERLY ${ }^{3}$ \\ B. PEYTON ${ }^{3}$
}

\begin{abstract}
${ }^{1}$ University of California at Davis Department of Civil and Environmental Engineering, Davis, CA 95616, USA

${ }^{2}$ Hellenic Ministry of Environmental Planning and Public Works Sewerage and Sewage Treatment (Varvaki 12, 11474, Athens, Greece ${ }^{3}$ Montana State University Department of Chemical and Biological Engineering Bozeman, MT 59717-3920, USA

\#Present address: Technical University of Crete Department of Environmental Engineering, 73100, Chania, Greece
\end{abstract}

Received: $23 / 10 / 08$

Accepted: 25/01/09 *to whom all correspondence should be addressed: e-mail: petrosgikas@gmail.com

\begin{abstract}
A mathematical model to simulate microbial growth and lag time is proposed in the present work in accordance with Sengor et al. (2009). The model is verified experimentally for a mixed microbial culture growing at metal free and at $\mathrm{Cr}(\mathrm{III})$ or $\mathrm{Cr}(\mathrm{VI})$ contaminated environments. The model is further verified using a monoculture of Pseudomonas sp. growing at metal free and $\mathrm{Zn}$ (II) contaminated environment. The effect of temperature on microbial growth and lag is also simulated by the model. The simulation results show for the mixed culture that growth rate decrease with parallel increase in lag time, with the rise of either $\mathrm{Cr}(\mathrm{III})$ or $\mathrm{Cr}(\mathrm{VI})$ concentration. For Pseudomonas sp., the simulation indicated that there is almost nil lag time for growth at $35^{\circ} \mathrm{C}$, while approximately $10 \mathrm{~h}$ lag time is calculated for growth at ambient temperature $\left(20^{\circ} \mathrm{C}\right)$. The lag time increases by approximately 6 more hours when $0.01 \mathrm{mM}$ $\mathrm{Zn}(\mathrm{II})$ is added in the growth medium (at ambient temperature). The increase of lag time with temperature reduction is explained by the fact that the biochemical reactions are slowed down at lower temperatures. A good correlation between model predictions and simulation results is observed.
\end{abstract}

KEYWORDS: modeling, heavy metals, metabolic lag, growth inhibition kinetics, microbial growth.

\section{INTRODUCTION}

Addition of trace amounts of heavy metals to the environment of microbial cells often stimulates microbial growth (Gikas, 2007; 2008). However, higher concentrations result in severe reduction of microbial activity, which is reflected by reduction of the apparent growth rate and increase in lag time. Heavy metal toxicity on microorganisms has been modeled previously by Utgikar et al. (2003) who studied the effects of $\mathrm{Cu}$ and $\mathrm{Zn}$ ions toxicity on sulfate-reducing bacteria. The authors considered constant biomass batch reactors (no net growth), and expressed initial cell death as a decreasing function of the heavy metal concentration. However, the authors (Utgikar et al., 2003) did not consider lag in degradation kinetics. Markwiese and Colberg (2000) have proposed a nonlinear regression model relating the lag time for an Iron-Reducing bacteria, but their work is mostly relevant for heavy-metal contaminated anaerobic sedimentary environments.

Heavy metals-induced delay in the increased in metabolic activity in response to substrate arrival, as well as oxygen mass transfer limitation during active aeration has been incorporated into microbial kinetics models by Sengor et al. (2009). Their model was extended 
from Ginn (1999) and Wood et al. (1995) by including the effect of heavy metals on the delayed microbial response to substrate appearance by developing an inhibitor-dependent metabolic potential functional to account for the metabolic state of the microorganisms. The concentration of the heavy metal was explicitly incorporated into the metabolic potential functional. In the present study, the validity of this model is further tested using three sets of experimental data. The first two sets deal with the growth of a mixed microbial culture growing on a carbon rich biomedium, at the presence of metal free and $\mathrm{Cr}(\mathrm{III})$ or $\mathrm{Cr}(\mathrm{VI})$ contaminated environment. The last set deals with the growth of a monoculture of Pseudomonas sp. growing at sterile conditions, at metal free (at two different temperatures) and at the presence of $0.01 \mathrm{mM} \mathrm{Zn(II).} \mathrm{The} \mathrm{model} \mathrm{takes} \mathrm{into} \mathrm{account} \mathrm{the} \mathrm{effect} \mathrm{of} \mathrm{oxygen} \mathrm{transport} \mathrm{via} \mathrm{diffusion,} \mathrm{by}$ introducing an interphase transfer flux proportional to the disequilibrium from Henry's law dictating equilibrium concentrations in aqueous (growth medium) and air (headspace) phases in accordance with Sengor et al. (2009).

\section{MODEL FORMULATION}

The proposed growth kinetics (Equations 1-4), including metabolic lag and oxygen diffusion in the aqueous phase are based on classical dual-Monod growth kinetic model.

$$
\begin{aligned}
& \frac{\mathrm{dM}}{\mathrm{dt}}=\mu \lambda(\mathrm{S}, \mathrm{C}) \mathrm{M}\left[\frac{\mathrm{S}}{\mathrm{S}+\mathrm{K}_{\mathrm{S}}}\right]\left[\frac{\mathrm{O}}{\mathrm{O}+\mathrm{K}_{\mathrm{O}}}\right] \\
& \frac{\mathrm{dO}}{\mathrm{dt}}=-\frac{\mathrm{F}}{\mathrm{Y}} \mu \lambda(\mathrm{S}, \mathrm{C}) \mathrm{M}\left[\frac{\mathrm{S}}{\mathrm{S}+\mathrm{K}_{\mathrm{S}}}\right]\left[\frac{\mathrm{O}}{\mathrm{O}+\mathrm{K}_{\mathrm{O}}}\right]+\frac{\mathrm{D}}{\mathrm{V}_{\text {aqu }}}\left(\mathrm{O}-\mathrm{O}_{\text {air }} / \mathrm{H}\right) \\
& \frac{\mathrm{dO}_{\text {air }}}{\mathrm{dt}}=-\frac{\mathrm{D}}{\mathrm{V}_{\text {air }}}\left(\mathrm{O}-\mathrm{O}_{\text {air }} / \mathrm{H}\right) \\
& \frac{\mathrm{dS}}{\mathrm{dt}}=-\frac{1}{\mathrm{Y}} \mu \lambda(\mathrm{S}, \mathrm{C}) \mathrm{M}\left[\frac{\mathrm{S}}{\mathrm{S}+\mathrm{K}_{\mathrm{S}}}\right]\left[\frac{\mathrm{O}}{\mathrm{O}+\mathrm{K}_{\mathrm{O}}}\right]
\end{aligned}
$$

Where: $M$ is the microbial biomass concentration; $S, O, O_{\text {air }}, C$ are the substrate, aqueous oxygen, headspace oxygen, and total metal concentrations, respectively; $K_{S}$ and $K_{O}$ are the half-saturation constants for substrate and aqueous oxygen, respectively; $\mu$ is the specific growth rate; $Y$ is the yield coefficient; $F$ is the oxygen utilization constant; $D$ is the interphase mass transfer coefficient; $H$ is the Henry's law constant; $V_{\text {air }}$ is the volume of the headspace air phase; $\lambda(S, C)$ is the metabolic potential, described by Equation 5 .

$$
\lambda\left(\mathrm{C}, \mathrm{S}^{*}\right)=\int_{0}^{\mathrm{t}} \mathrm{K}(\tau ; \mathrm{C}) \mathrm{S}^{*}(\mathrm{t}-\tau) \mathrm{d} \tau
$$

Where $K(\tau, \mathrm{C})$ is the memory, or kernel function defined as:

$$
\mathrm{K}(\tau, \mathrm{C})=\left[H^{\prime}\left(\tau-\alpha C^{\prime}\right)-H^{\prime}\left(\tau-\alpha C^{\prime}-\Delta\right)\right] \cdot\left(\frac{1}{\Delta}\right)
$$

Where: $H^{\prime}(x)$ is a smoothed heaviside function as described by Ginn (1999). The metabolic potential functional, $\lambda[\mathrm{S}, \mathrm{C}]$, is extended from Ginn (1999) and Wood et al. (1995). This functional dates back to Powell (1967) and is originally cast as a representation of the history of exposure of microbes to substrate $S$. $S^{*}$ is a threshold indicator function that reflects ambient trophic conditions. $S^{*}(t)=1$ if the substrate concentration at time $t$ exceeds that needed to initiate transformation of resting cells to active state, and zero otherwise. The kernel function can take many empirical forms but in all cases dictates the kinetics of transformation of cells from resting to active states (and vice versa). In particular this kernel includes a lag that is dependent on the local heavy metal concentration $C$. An initial lag of length $\alpha C^{\prime}$ during which there is no increase in metabolic activity is then followed by a rampup interval of length $\Delta$ during which metabolic activity rises to unity. The metabolic potential is quantified in this way by use of a convolution (Equation 5) between historical substrate concentration and a memory kernel function that is a uniform distribution that begins at time 
$\alpha C^{\prime}$ and lasts until time $\alpha C^{\prime}+\Delta$, where $\alpha$ is the lag parameter and $C^{\prime}$ is the difference between the local metal concentration and a threshold metal concentration, above which metabolic change is induced and below which it is not. The integration in (5) is over history, i.e., time before present, indicated by $\Delta$. The lag parameter $\alpha$ is fitted to data per metal, while the ramp-up interval $\Delta$ is taken to be 4 hours for all experiments.

The simulations demonstrate the ability of a simple linear lag model to reflect impacts of toxic chemicals such as excess heavy metals. In all experiments analyzed here the effects of three metals species $(\mathrm{Cr}(\mathrm{III}), \mathrm{Cr}(\mathrm{VI})$ and $\mathrm{Zn}(\mathrm{II}))$ applied individually were essentially captured in terms of increased lag, and yield coefficient. The model developed here helped identify this parsimonious expression of the kinetics on metals, but was also able to accommodate dependencies of other kinetic parameters such as specific growth rate on dose of toxic materials.

\section{MATERIALS AND METHODS}

\subsection{Experimental set-up for the mixed microbial culture growing at the presence of $\mathrm{Cr}(\mathrm{III})$ and $\mathrm{Cr}(\mathrm{VI})$}

The mixed microbial inoculum was collected from the aeration tank of the wastewater treatment plant of Athens, in Psyttalia Island. The microbes were grown in a batch system with continuous aeration, on a carbon rich medium. Calculated amounts of either $\mathrm{Cr}\left(\mathrm{NO}_{3}\right)_{3}$ or $\mathrm{K}_{2} \mathrm{Cr}_{2} \mathrm{O}_{7}$ were added in the growth medium, to yield final concentrations of $5,10,20,30,40$, 80 and $160 \mathrm{mg} \mathrm{I}^{-1}$ of $\mathrm{Cr}(\mathrm{III})$ or $\mathrm{Cr}(\mathrm{VI})$, respectively. Dextrose, peptone and yeast extract (at a weight ratio 2:3:2) were used as carbon source in the biomedium. The experimental setup, biomedium composition, and analytical techniques have been described elsewhere (Gikas and Romanos, 2006).

\subsection{Experimental set-up for the monoculture of Pseudomonas sp growing at the presence of $\mathrm{Zn}$ (II)}

The Pseudomonas sp. used in the present experiments had been isolated from the hot springs of the Yellowstone National Park, Wyoming, USA. Cells were grown in $100 \mathrm{ml}$ shake flasks, mounted on a rotary shaker; at maximum, 1:3 of the flask volume was occupied the biomedium. Experiments were carried out in sterile conditions, at ambient temperature (20 ${ }^{\circ} \mathrm{C}$ ). Cells were grown on a carbon rich, defined medium (Moberly, 2006), using glucose as sole carbon source and with the calculated amounts of zinc (as $\mathrm{ZnCl}_{2}$ ) added. The amount of oxygen in the headspace was sufficient for the compete conversion of glucose to carbon dioxide. Optical density of the culture was measured using a Genesys ${ }^{\mathrm{TM}} 10$ Series Spectrophotometer (Thermo Electron Corporation, USA).

\section{RESULTS AND DISCUSSION}

\subsection{Exposure of mixed microbial culture to $\mathrm{Cr}(\mathrm{III})$ and $\mathrm{Cr}(\mathrm{VI})$}

The model formulation for the microbial metabolic lag as a functional of the history of the heavy metal concentration is applied for the growth of the mixed culture, as it is described in paragraph 3.1. The experimental and model predicted biomass concentrations for the mixed microbial culture in the presence of the above concentrations of $\mathrm{Cr}(\mathrm{III})$ and $\mathrm{Cr}(\mathrm{VI})$ are depicted in Figures 1 and 2, respectively. It is seen from Figures 1 and 2 that exposure of microorganisms to increasing levels of either $\mathrm{Cr}(\mathrm{III})$ or $\mathrm{Cr}(\mathrm{VI})$ results to the reduction of total biomass concentrations as well as to increase of the relative lag times. This increase in the lag times is simulated by the use of the metabolic potential functional $\lambda$, where the lag times are obtained to be $3.5,3.7,4.0,4.4,4.7,6.0$ and $9.0 \mathrm{~h}$ for $5,10,20,30,40,80$ and $160 \mathrm{mg} \mathrm{l}^{-1}$ $\mathrm{Cr}(\mathrm{III})$, respectively (Table 1). The kinetic parameters in the presence of $\mathrm{Cr}(\mathrm{VI})$ have been calculated similarly as for $\mathrm{Cr}(\mathrm{III})$ (They are not presented here). In the presence of $\mathrm{Cr}(\mathrm{VII}$ ), the yield coefficients are slightly lower and the lag times are slightly higher, compared to the ones in the presence of $\mathrm{Cr}(\mathrm{III})$, probably reflecting the relatively higher toxicity $\operatorname{of} \mathrm{Cr}(\mathrm{VI})$ to the microbes (Gikas and Romanos, 2006a; 2006b). At the Cr-free control cases, there still exists a lag time (lag parameter of length $3.0 \mathrm{~h}$ ), which may be attributed to delayed metabolism of 
the substrate just after inoculation, as during this period of time the cells are transformed from dormant to active (Wood et al., 1995).

The kinetic parameter values used in modeling the biomass concentrations, in Equations (15 ), at the presence of $\mathrm{Cr}(\mathrm{III})$, are given in Table 1, where the inhibited growth parameters have been measured or inferred by fitting the experimental data. The initial concentrations of biomass and carbon source were measured and the initial oxygen was calculated from equilibria at the laboratory. It is seen from Figures 1 and 2 that the growth phase of the culture (during the time of the experiment) resembles more closely to a linear than to an exponential function, possibly suggesting mass transfer limitation of oxygen during the growth process. In order to account for this limitation, a mathematical formulation is incorporated within the Monod biodegradation kinetics in accordance with Sengor et al. (2009). As a result of this limitation, the rising optical density curve that defines growth in these experiments may have a slope that is defined not by the true specific growth rate but rather by the oxygen availability within the biomedium, and thus, $D$ was used as a fitting parameter for the slope of the growth curve. Thus, if oxygen was treated to be non-limiting during growth, then the model-predicted growth curves would have exponential shape (not shown), instead of linear (Figures 1 and 2). Consequently the fitting of the kinetics model was accomplished without different values of the specific growth rate per metal dose; in fact the specific growth rate was found invariant with metals dose. Thus the toxic effects of the metals may have changed the effective value of the specific growth rate; however, in light of the fact that the specific growth rates used were identical to the values used in the metal-free controls, it is clear that any such cloaked changes in the effective specific growth rate were so small that they evidently did not appreciably change the rate at which oxygen was utilized in the biodegradation. Due to the lack of carbon source measurements during the experiments (apart from the initial concentration), the yield coefficients were fitted to the data, by expressing all carbon sources in equivalent carbon mass of glucose. The value of $K_{s}$ was estimated from Metcalf and Eddy (2002) and the value of $K_{o}$ was estimated from Chen et al. (2003) and Seker et al. (1997). It is also observed that it was the $K_{o}$ and not $K_{s}$ that was governing the biomass curve by and thus the model fit was not sensitive to $K_{s}$ Using the microbial lag model, the lag parameter $\alpha$ was fitted to data per metal but not varying between treatments, and the ramp-up interval $\Delta$ was taken to be 4 hours for all experiments. Thus here we used only lag and yield coefficient to signal metals exposure, parsimoniously. Similarly, for the application of $\mathrm{Cr}(\mathrm{VI})$ toxicity, the kinetic parameters were measured or inferred by fitting the experimental data as described above.

Table 1. Kinetic parameters for $\mathrm{Cr}(\mathrm{III})$ inhibited growth of the mixed microbial culture, at various $\mathrm{Cr}(\mathrm{III})$ concentrations

\begin{tabular}{|c|c|c|c|c|c|c|c|c|}
\hline \multirow{2}{*}{ Model parameter } & \multicolumn{8}{|c|}{$\mathrm{Cr}(\mathrm{III})$ concentration $\left(\mathrm{mg} \mathrm{I}^{-1}\right)$} \\
\hline & 0 & 5 & 10 & 20 & 30 & 40 & 80 & 160 \\
\hline$\mu^{1},\left(1 \mathrm{~h}^{-1}\right)$ & 0.5 & 0.5 & 0.5 & 0.5 & 0.5 & 0.5 & 0.5 & 0.5 \\
\hline$K_{s},\left(\mathrm{mg} \mathrm{l}^{-1}\right)$ & 40 & 40 & 40 & 40 & 40 & 40 & 40 & 40 \\
\hline $\begin{array}{l}\text { Y, (mg biomass per } \\
\text { mq substrate }^{2} \text { ) }\end{array}$ & 1.1 & 1.3 & 1.4 & 1.0 & 0.9 & 0.8 & 0.55 & 0.3 \\
\hline$K_{o}^{1,3},\left(\mathrm{mg} \mathrm{l}^{-1}\right)$ & 0.05 & 0.05 & 0.05 & 0.05 & 0.05 & 0.05 & 0.05 & 0.05 \\
\hline $\mathrm{D},\left(\mathrm{I} \mathrm{h}^{-1}\right)$ & 14 & 14 & 14 & 14 & 14 & 14 & 14 & 14 \\
\hline$\alpha C^{\prime},(h)$ & 3.0 & 3.5 & 3.7 & 4.0 & 4.4 & 4.7 & 6.0 & 9.0 \\
\hline $\mathrm{M}(0)^{4},\left(\mathrm{mg} \mathrm{l}^{-1}\right)$ & 123 & 123 & 123 & 123 & 123 & 123 & 123 & 123 \\
\hline $\mathrm{A}(0)^{3,4},\left(\mathrm{mg} \mathrm{l}^{-1}\right)$ & 7000 & 7000 & 7000 & 7000 & 7000 & 7000 & 7000 & 7000 \\
\hline $\mathrm{O}(0)^{4},\left(\mathrm{mg} \mathrm{l}^{-1}\right)$ & 6.4 & 6.4 & 6.4 & 6.4 & 6.4 & 6.4 & 6.4 & 6.4 \\
\hline
\end{tabular}


Both, the experimental results and the model predictions indicate a reduction of maximum biomass concentration with the increase of heavy metal concentration (Figures 1 and 2). This is represented through a decrease in the yield coefficient, $Y$ (see Table 1 for $\mathrm{Cr}$ (III)) with increasing metal concentration. This implies that the amount of biomass produced per mass substrate drops as the biomass is exposed to higher amounts of heavy metal. This might be explained by the higher requirements for maintenance energy in the presence of heavy metals (Giller et al., 1998) or due to cell lysing as an effect of the exposure to heavy metals, as growth was measured by measuring the optical density and lysed cells do not absorb. In the first case, the microorganisms expend energy to repair the cell damages caused by the metal toxicity, or because they have to use alternative enzymatic pathways to adapt to the new environmental conditions, or in order to counterbalance osmotic requirements across cellular membranes. Thus, as the metal concentration increases, more energy is required for cell maintenance, and thus less substrate is available for microbial growth.

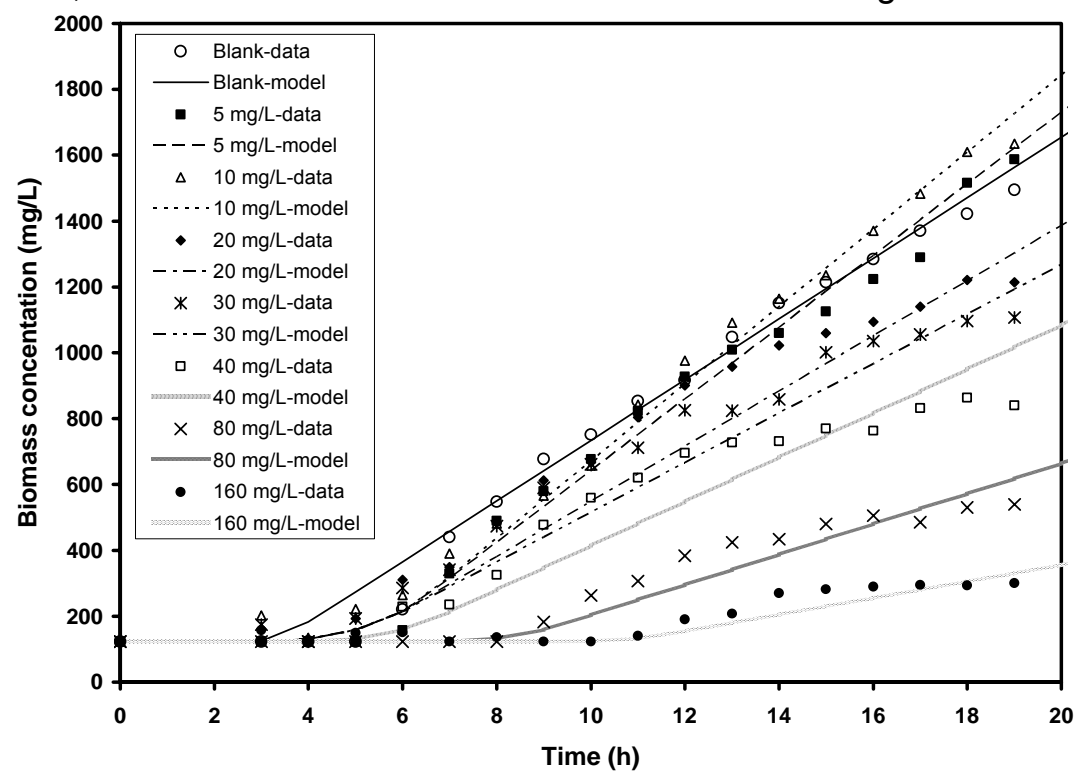

Figure 1. Experimental and model predicted biomass concentrations for growth of a mixed microbial culture in the presence of metal free and $5,10,20,30,40,80$ and $160 \mathrm{mg} \mathrm{I}^{-1} \mathrm{Cr}(\mathrm{III})$

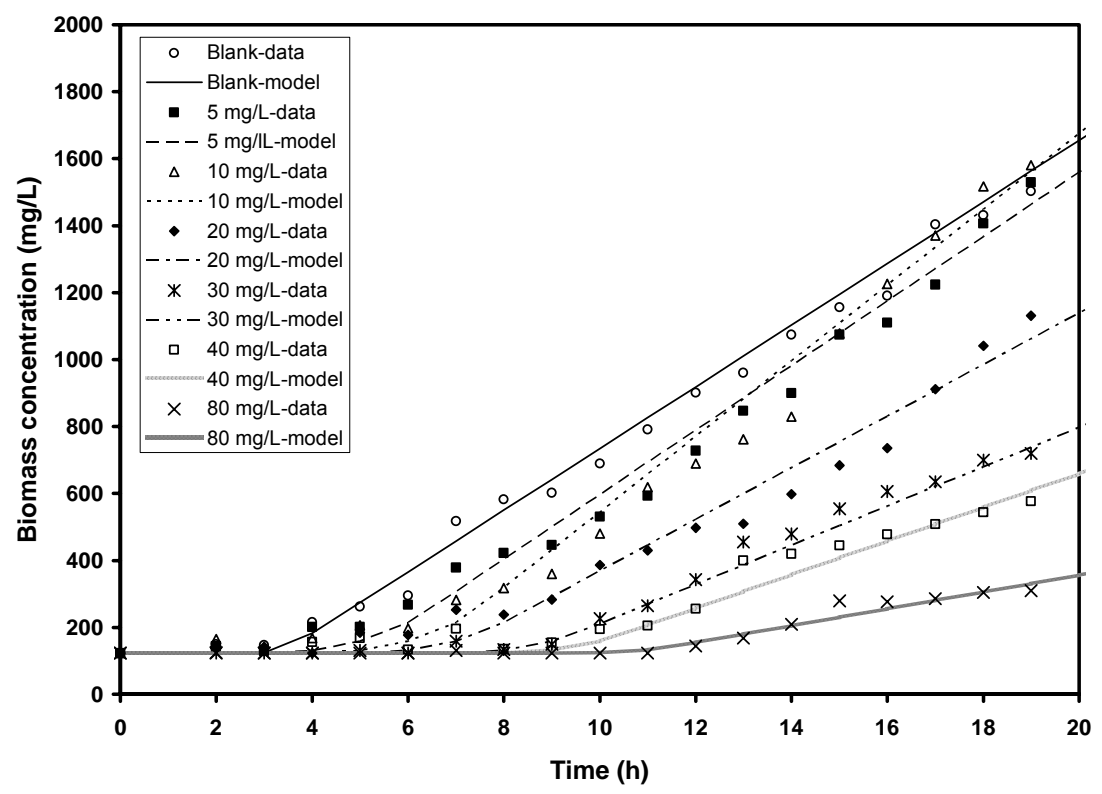

Figure 2. Experimental and model predicted biomass concentrations for growth of a mixed microbial culture in the presence of metal free and 5, 10, 20, 30, 40 and $80 \mathrm{mg} \mathrm{l}^{-1} \mathrm{Cr}(\mathrm{VI})$ 


\subsection{Exposure of Pseudomonas sp. to Zn}

The same model for biomass growth in the presence of $\mathrm{Zn}$ is applied to simulate the growth of Pseudomonas sp. growing on a carbon rich medium. The two out of three individual sets of trials involve microbial growth at metal free conditions and at the presence of $0.01 \mathrm{mM} \mathrm{Zn(II),}$ at ambient temperature $\left(20^{\circ} \mathrm{C}\right)$. The third set involves the growth of the same microbial specie, at metal free environment, at $35^{\circ} \mathrm{C}$ (Figure 3). The results show that there is almost nil lag time for the Pseudomonas sp. growing at $35^{\circ} \mathrm{C}$, while approximately $10 \mathrm{~h}$ lag time is observed for growth at ambient temperature. The lag time increases by approximately 6 more hours when $0.01 \mathrm{mM} \mathrm{Zn(II)}$ are added in the growth medium (at ambient temperature). The lag times are obtained to be 8 and $15 \mathrm{~h}$ for metal-free growth and at the presence of $0.01 \mathrm{mM}$ $\mathrm{Zn}(\mathrm{II})$, at ambient temperature, respectively. At metal free growth, at $35^{\circ} \mathrm{C}$, the lag time is obtained to be zero. The increase of lag time with temperature reduction is explained by the fact that the biochemical reactions are slowed down at lower temperatures. Thus, dormant cells require more time to shift into actively growing cells.

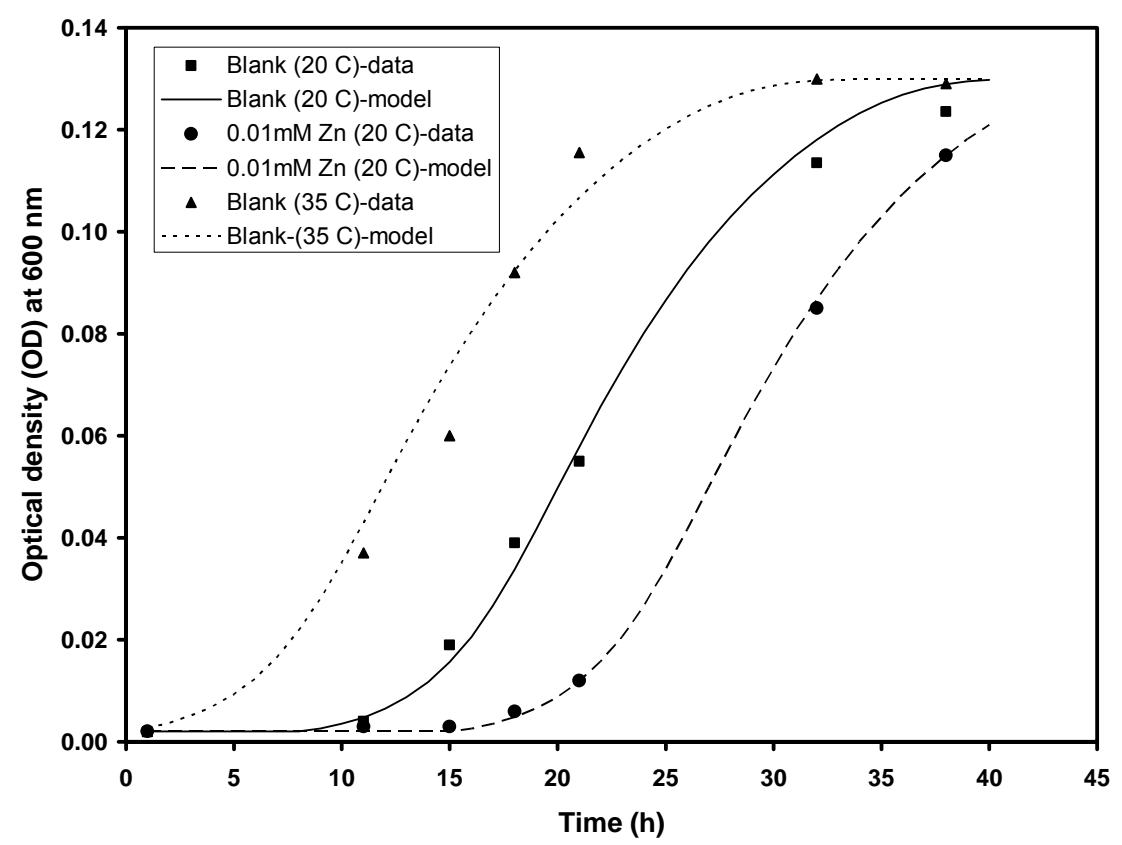

Figure 3. Experimental and model predicted biomass concentrations for growth of Pseudomonas sp. at the presence of metal free $\left(20^{\circ} \mathrm{C}\right), 0.01 \mathrm{mM} \mathrm{Zn}(\mathrm{II})\left(20^{\circ} \mathrm{C}\right)$ and metal-free $\left(35^{\circ} \mathrm{C}\right)$

It is also seen from Figure 3 that the growth phase of Pseudomonas. sp. does not follow a definite sigmoid trend, possibly suggesting oxygen mass transfer limitation during the growth process. The model predictions also indicate that the biomass growth is controlled by the oxygen diffusion parameter, $D$, where the mathematical formulation is incorporated within the Monod biodegradation kinetics to account for this limitation (Equations 1-4). Therefore, here we also used only lag and yield coefficient to signal metals exposure, parsimoniously, as described for the first application in section 4.1.

The model predictions also indicate that the biodegradation reactions become inhibited at about 30 and $40 \mathrm{~h}$ in the presence of metal free growth at ambient temperature $\left(20^{\circ} \mathrm{C}\right)$, and at metal-free at $35^{\circ} \mathrm{C}$, respectively, which is most probably due to carbonaceous substrate limitation (as the total amount of oxygen inside the shaking flasks was enough for the complete oxidation of glucose). The model predicted substrate concentrations in the above mentioned growth cases are shown in Figure 4, where the time of growth interception corresponds to the time of substrate depletion (Figures 3 and 4). In the presence of $0.01 \mathrm{mM}$ $\mathrm{Zn}$ concentration, due to the delayed response of Pseudomonas. sp., there is still some substrate available for biodegradation at the end of the experiment; and hence more potential 
for biomass growth, if the experiment was to be carried out for a longer time (Figures 3 and 4). Although the substrate concentrations were not measured during the experiments, the mathematical model provides a possible explanation about the system behavior. It is seen from Figures 3 and 4 that modeling microbial lag is needed to capture the delay in biodegradation and thus without the lag model, the sequencing of the curves corresponding to each of the metal treated batch experiments would not be achieved.

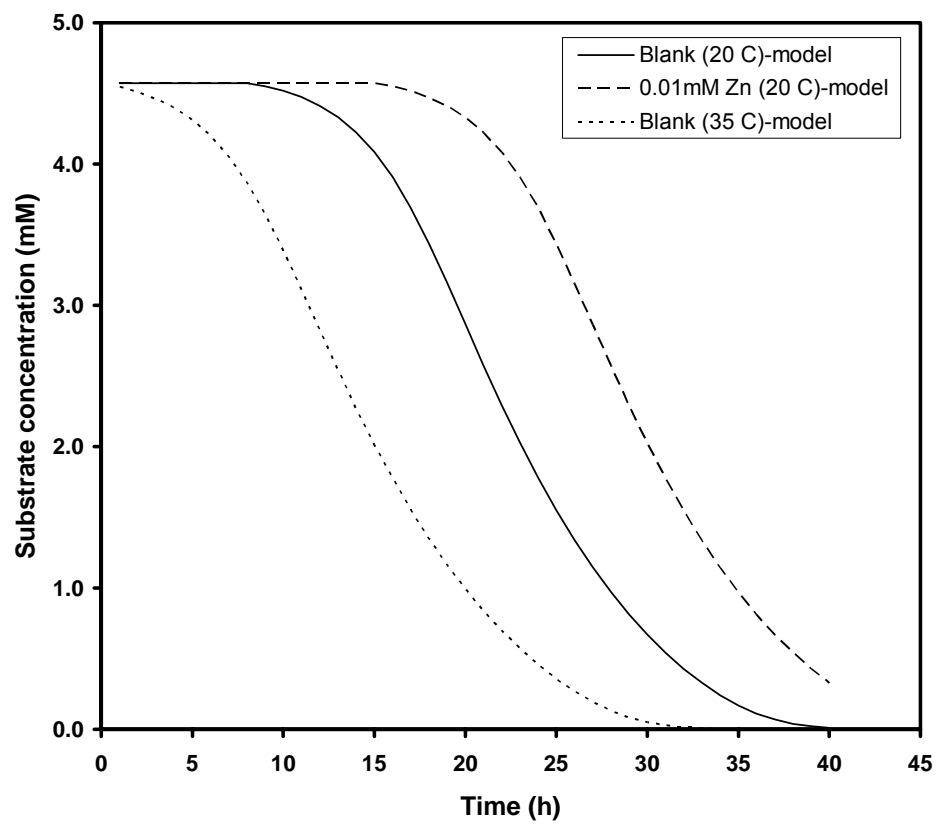

Figure 4. Model predicted substrate concentrations for growth of Pseudomonas sp. at the presence of metal free $\left(20^{\circ} \mathrm{C}\right), 0.01 \mathrm{mM} \mathrm{Zn}(\mathrm{II})\left(20^{\circ} \mathrm{C}\right)$ and metal-free $\left(35^{\circ} \mathrm{C}\right)$

\section{CONCLUSIONS}

A microbial growth kinetic model to simulate biomass growth, substrate biodegradation and lag time in the presence of heavy metals has been proposed in accordance with (Sengor et al. in press). In this work, the model which has been previously described by Ginn (1999) and Wood et al. (1995), is extended by including the effect of heavy metals on the delayed microbial response to substrate appearance by developing an inhibitor-dependent metabolic potential functional to account for the metabolic state of the microorganisms. The concentration of the inhibiting heavy metal was explicitly incorporated into the metabolic potential functional. In the present study, we have used this model to describe microbial growth for a mixed culture growing on a rich carbon source and in the presence of either $\mathrm{Cr}(\mathrm{III})$ or $\mathrm{Cr}(\mathrm{VI})$, and for the growth of a monoculture of Pseudomonas sp. in the presence of metal free growth medium at ambient temperature $\left(20^{\circ} \mathrm{C}\right)$, at $35^{\circ} \mathrm{C}$ and at the presence of $0.01 \mathrm{mM}$ at $35^{\circ} \mathrm{C}$. The simulations suggested that oxygen was limited in all cases. This limitation was accounted through a mathematical formulation incorporated within the Monod biodegradation kinetics as described by Sengor et al. (2009). The model effectively predicted the lag times and biomass concentration in all cases, despite the peculiar behavior of microbial growth due to oxygen limitation.

\section{ACKNOWLEDGMENTS}

The authors wish to thank Dr. Nicolas Spycher from the Lawrence Berkeley Laboratory, CA, for the valuable discussions on the theoretical aspects of the model development. 


\section{REFERENCES}

Chen F., Xia Q. and Ju L.K. (2003) Aerobic Denitrification of Pseudomonas aeruginosa monitored by online NAD(P)H fluorescence, Applied Environmental Microbiology, 69, 6715-6722.

Gikas P. and Romanos P. (2006a) Activated sludge growth stimulation and inhibition by $\mathrm{Cr}(\mathrm{III})$, $\mathrm{Cr}(\mathrm{VI}), \mathrm{Ni}(\mathrm{II})$ and $\mathrm{Cd}(\mathrm{II})$, In: Proc. Int. Conf. Protection and Restoration of the Environment VIII, E. Gidarakos, N. Nikolaidis and C. Christodulatos (eds), Chania, Greece, 259-260.

Gikas P. and Romanos P. (2006b) Effects of tri-valent $(\mathrm{Cr}(\mathrm{III}))$ and hexa-valent $(\mathrm{Cr}(\mathrm{VI}))$ chromium on the growth rate of activated sludge, Journal of Hazardous Materials, B133, 212-217.

Gikas P. (2007) Kinetic responses of activated sludge to individual and joint nickel (Ni(II)) and cobalt (Co(II)) - an isobolographic approach, Journal of Hazardous Materials, 143, 246-256.

Gikas P. (2008) Single and combined effects of nickel (Ni(II)) and cobalt $(\mathrm{Co}(\mathrm{II}))$ ions on activated sludge and on other aerobic microorganisms: A review, Journal of Hazardous Materials, 159, 187-203.

Giller K.E., Witter E. and McGrath S.P. (1998) Toxicity of heavy metals to microorganisms and microbial processes in agricultural soils: A review, Soil Biology and Biochemistry, 30, 13891414.

Ginn T.R. (1999) On the distribution of generalized exposure-time in groundwater flow and reactive transport: foundations; formulations for groundwater age, geochemical heterogeneity, and biodegradation, Water Resources Research., 35, 1395-1408.

Markwiese J.T. and Colberg P.J.S. (2000) Bacterial reduction of copper-contaminated ferric oxide: Copper toxicity and the interaction between fermentative and iron-reducing bacteria, Archives of Environmental Contamination and Toxicology, 38, 139-146.

Metcalf and Eddy Inc, Tchobanoglous G., Burton F. and Stensel H.D. (2002) Wastewater Engineering: Treatment and Reuse. McGraw-Hill Science Engineering, New York, NY, USA.

Moberly J.G. (2006) Biogeochemical cycling of toxic metals in Lake Coeur d'Alene sediments, Masters Thesis, Washington State University, Pullman, WA, USA.

Powell E.O. (1967) The growth rate of microorganisms as a function of the substrate concentrations. In: Microbial Physiology and Continuous Culture. Her Majesty's Stationery Office, E.D. Powell, C.G.T. Evans, R.E. Strange, and D.W. Tempest (eds.), London, England. 34-56.

Seker S., Beyenal H., Salih B. and Tanyolac A. (1997) Multi-substrate growth kinetics of Pseudomonas putida for phenol removal, Applied Microbiology and Biotechnology, 47, 610614.

Sengor S.S., Barua S., Gikas P., Ginn T.R., Peyton B., Sani R.K. and Spycher N. (2009) Influence of heavy metals on microbial growth kinetics including lag time: Mathematical modeling and experimental verification, Environmental Toxicology and Chemistry, 28(10), 2020-2029.

Utgikar V.P., Tabak H.H., Haines J.R. and Govind R. (2003) Quantification of toxic and inhibitory impact of copper and zinc on mixed cultures of sulfate-reducing bacteria, Biotechnology and Bioengineering, 83, 306-312.

Wood B.D., Ginn T.R. and Dawson C. (1995) Effects of microbial metabolic lag in contaminant transport and biodegradation modeling, Water Resources Research, 31, 553-563. 